\title{
Development of a Low Cost Ventilator using a Proportional Solenoid Valve
}

\author{
T. Owodolu ${ }^{1}$, J. Azeta ${ }^{1}$, C. A. Bolu ${ }^{1}$ \\ ${ }^{1}$ Department of Mechanical Engineering, Covenant University, Ota, Ogun state, Nigeria \\ *Corresponding author, email: joseph.azeta@ covenantuniversity.edu.ng
}

Received Date : September 01, 2021 Accepted Date : September 24, 2021 Published Date : October 07, 2021

\begin{abstract}
This paper describes the development of portable mechanical ventilator using a proportional solenoid valve whose aim is to regulate the flow rate of oxygen to the patient together with an Arduino Mega2560 as the main controller for the machine before delivering the required volume to the patient; base on their ideal body weight so as to prevent blowing out the lungs The aimed of this development is to save and improve the quality of lives of patients with respiratory problems rather than replacing the existing ventilator. Furthermore, test analysis was conducted to evaluate its performance and also the comparative analysis between the standard and the developed ventilator showed the reasons why most hospitals don't have ventilators.
\end{abstract}

Key words: mechanical ventilator, oxygen, proportional solenoid valve, respiratory

\section{INTRODUCTION}

Mechanical ventilation has become the most widely utilized mode of life support in clinic today due to high frequently identifiable source of nosocomial infection at the intensive care unit [1]. It is a lifesaving treatment commonly utilized in critical care unit to mechanically ventilate critically ill patients [2]. Furthermore, researches have shown lung and breathing problems to be one of the major causes of death in world. In the early 90's, the aforementioned respiratory disease was the sixth most common cause of death across the globe before becoming the third most deadly in the year 2020 [3]. Patients diagnosed with this disease require respiratory support for different reasons ranging from medical complications to emergent surgical interventions. From various researches carried out, death rates in area with respiratory failure have been observed to be minimized where mechanical ventilation with evidence-based approaches is mandatory. One of the major function of mechanical ventilation is to mechanically assist or replace spontaneous breathing by utilizing an apparatus to enhance the transport of oxygen and carbon dioxide between the atmosphere and the alveoli for the purpose of enhancing pulmonary gas exchange due to the inability of patient to maintain airway [4].

Researchers came to a consensus that mechanical ventilation can damage the lungs and this is triggered by a condition known as ventilation-induced lung injury. The two most common types of damage been identified are volutrauma and atelectrauma [5]. Volutrauma appears when the ventilation in excess causes over-stretching of the corresponding lung parenchyma thereby triggering an inflammatory reaction that result to the damage of the alveolar walls and edema. More so, atelectrauma which result from insufficient ventilation permits the alveolar units to collapse and reopen, in a recurring, chronological movement due to absence of positive end-expiratory pressure (PEEP) in the mechanical ventilation [6]. In view of the fact that mechanical ventilators potentially expose the patient's lungs to damage, all initiatives of constructing low-cost mechanical ventilators are yet to provide the regulation of lung's pressure and positive end-expiratory pressure [7]. The major point involves regulating the machine to prevent excessive pressure, which is a side effect of the excess energy from the ventilator machinery [8]. Literature studies from [9] described historical review of different methods of mechanical ventilation. The researchers stated that, artificial ventilation has been in existence since biblical times while modern and automatic devices came to existence in the early 1800s. Also, [10] postulated different kinds of portable ventilators and their historical development. They described the concept to be new as compared to the ventilator in the intensive care unit. Portable ventilators were described to evolve due to the necessity of ventilating a patient when shifting or moving from one location to another. Furthermore, [12] automated BVM mechanically to construct a portable mechanical ventilator. The author used cam mechanism in the work to produce the desired motion of the BVM. This paper discusses the development of low cost mechanical ventilator using proportional solenoid valve that would meet a patient's respiratory demand and minimize reliance on a ventilator in areas where it is unavailable and inaccessible. Healthcare needs a pathfinder solution in which the investment and risk of an automated application is small [13], [14]. 
T. Owodolu et al., International Journal of Emerging Trends in Engineering Research, 9(10), October 2021, 1357 - 1360

\section{Methodology}

Table 1: Components

\begin{tabular}{|c|c|c|}
\hline $\mathrm{S} / \mathrm{N}$ & Component & Specifications \\
\hline 1 & AD620 Module & \\
\hline 2 & $\begin{array}{l}\text { Proportional } \\
\text { solenoid valve }\end{array}$ & Working Current( $(<=500 \mathrm{MA})$ \\
\hline 3 & $\begin{array}{l}\text { Graphic LCD } \\
\text { Screen }\end{array}$ & GLCD $128 * 64$ pixels \\
\hline 4 & Microcontroller & ATmega2560 \\
\hline 5 & $\begin{array}{l}\text { Hand Gesture (GY- } \\
\text { PAJ7620) }\end{array}$ & $\begin{array}{l}\text { general } 12 \mathrm{C} \text { interface into a single } \\
\text { chip }\end{array}$ \\
\hline 6 & Relay switch & $12 \mathrm{~V}$ \\
\hline 7 & $\begin{array}{l}\text { Differential pressure } \\
\text { sensor (MPX10D) }\end{array}$ & $\begin{array}{l}\text { OKPa }-10 \mathrm{KPa}_{2}-2 \mathrm{kPa} \text { to }+2 \mathrm{kPa} \\
\text { (Vacuum) }\end{array}$ \\
\hline 8 & $\begin{array}{l}\text { Oxygen Gas } \\
\text { regulator flow meter }\end{array}$ & \\
\hline 9 & $\begin{array}{l}\text { Flow sensor and } \\
\text { Flow meter }\end{array}$ & $\begin{array}{l}5-18 \mathrm{~V} \text { to maximum operating current } \\
\text { of } 15 \mathrm{~mA} \text { (DC } 5 \mathrm{~V} \text { ). }\end{array}$ \\
\hline 10 & Buzzer & \\
\hline 11 & Potentiometer & \\
\hline 12 & Plumbing fittings & $\begin{array}{l}\text { 3/8 MNPT } * 3 / 8 \text { Barb Brass } \\
900^{\circ} \text { Elbow } \\
\text { 3/8 MNPT Thread Barb * NPT Hose } \\
\text { Insert, } 3 / 8 * 3 / 8 \text { Union Connector } \\
3 / 8^{n} \text { Compression * } 3 / 8 \text { Male Pipe } \\
\text { Thread Adapter } 3 / 8 * 3 / 8 N P T \text { Street } \\
\text { Tee (2) } 1 / 2 " 1 / 4^{\prime \prime} \text { Connector (1) } \% / 4 \\
\text { MNPT Tee (1) }\end{array}$ \\
\hline
\end{tabular}

The materials and equipment were selected on the basis of design assumptions. Materials used to construct the prototype are presented in Table 1.

\subsection{Operation of the Mechanical Ventilator}

The developed ventilator operates under a volume controlled ventilation mode where flow is regulated until a maximum pressure is attained and pressure itself is further regulate to prevent buildup of pressure in the system. There are two major components at the heart of the ventilator: The proportional solenoid valve and the Arduino ATMega2560. The entire project is divided into two parts: the inspiratory path and the expiratory path. The inspiratory path consists of the mass flow pressure regulator, proportional solenoid valve and the flow sensor. At the initiation of the ventilator as shown in Figure 1, the compressed oxygen gas stored in the oxygen cylinder is regulated to $\sim 17 \mathrm{PSI}$ and sent to the proportional solenoid valve to generate a precise flow under the control of a PMW electrical signal from the microcontroller. The flow through the plumbed pipe fittings is measured via a flow sensor and an I2C signal is sent back to the microcontroller to close the loop.

The hand gesture controller was adopted instead of knobs to control and navigate the GLCD module. Four modes with different parameters were set based on the patient's physiology and disease. The required volume is continuously delivered to the patient based on their ideal body weight while regulating pressure to remain at the barest minimum in order to avoid blowing out the lungs.

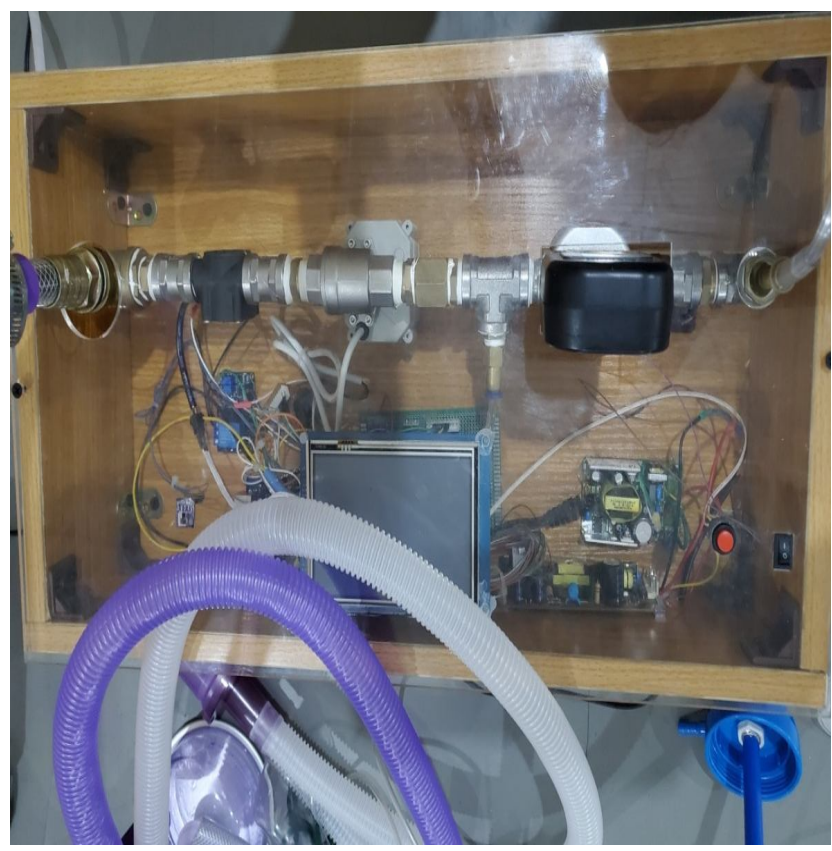

Figure 1: Ventilator Setup

\subsection{Electronic Design}

The resistor connected in series to a capacitor as shown in Figure 2 represent the basic electrical model. In other words, it might also consist of two lungs, chest wall, and properties of ventilator circuit. Taking a good look at the pressure (voltage), volume (charge), and flow (current), it is evidence that this model is an overview of the real biological respiratory system. Furthermore, equate of motion for respiratory system connects pressure, volume, and flow during ventilation and it is given as;

Pmus + Pvent $=$ R.V + E.V.

Where Pmus represents the pressure produced by the respiratory muscle, Pvent is the pressure produced by the ventilator, elastance, lung volume and the resistance of a respiratory system are denoted by $\mathrm{E}, \mathrm{V}$ and $\mathrm{R}$.During mechanical ventilation, muscle pressure, the pressure of the ventilator, volume, flow equates to zero while elastance and resistance remain constant 


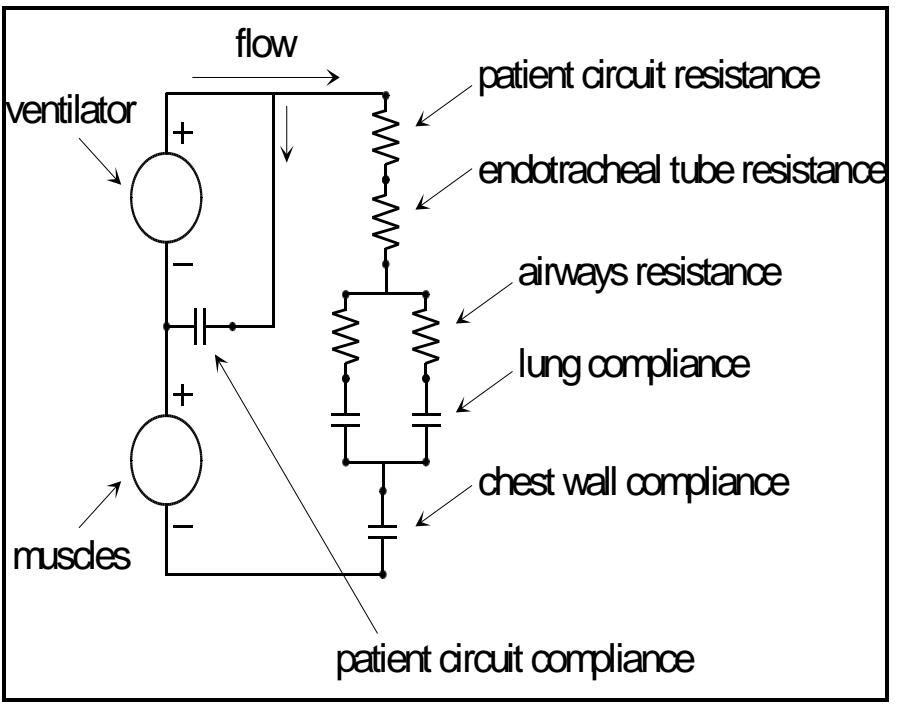

Figure 2: Electronic Model of Patient Ventilator System

\subsection{Design Assumptions and calculation}

To determine the Tidal volume to be delivered to the patient. In adults, an ideal tidal volume between 6 and $8 \mathrm{~mL}$ per $\mathrm{kg}$ of body mass is recommended. Also, the size of the endotracheal tube (ETT) varies and it is dependent of the patient's height. It ranges from $2 \mathrm{~mm}$ to $10.5 \mathrm{~mm}$. To calculate the tidal volume, we need to determine the depth of the ETT insertion.

Let us assume we want to ventilate a 52 year old man whose height is $161 \mathrm{~cm}$ (63.39in)

$$
\text { ETT }[\mathrm{cm}]=0.1 * \text { height }[\mathrm{cm}]+4
$$

(2)

$$
\begin{aligned}
& \text { ETT }[\mathrm{cm}]=0.1 * 161[\mathrm{~cm}]+4 \\
& \quad=20.1 \mathrm{~cm} .
\end{aligned}
$$

To calculate the ideal body weight (IBW) of a male:

IBW $(\mathrm{Kg})=50+0.9 *($ height $[\mathrm{cm}]-152$

IBW $(\mathrm{Kg})=50+0.9 *(161-152)$

$$
=58.1 \mathrm{Kg}
$$

Therefore, is tidal volume should be around 6 and $8 \mathrm{~mL} / \mathrm{kg}$ of body mass.

For $6 \mathrm{~mL} / \mathrm{kg}$ :

$6 * 58.1=348 \mathrm{ml}$.

For $8 \mathrm{~mL} / \mathrm{kg}$ :

$8 * 58.1=464.8 \mathrm{ml}$

i. Maximum power consumed by the ventilator

At idle state:

$\mathrm{I}=0.04 \mathrm{Amp}$

$\mathrm{V}=217 \mathrm{v}$

$\mathrm{P}=\mathrm{IV}(0.52)$

$=0.04 * 217 * 0.52$

$=4.5136 \mathrm{~W}$.

At working state:

$\mathrm{I}=0.05 \mathrm{Amp}$

$\mathrm{V}=217 \mathrm{v}$

$\mathrm{P}=\mathrm{IV}(0.52)$

$=0.05 * 217 * 0.52$
$=5.642 \mathrm{~W}$.

ii. To calculate the flow rate:

Flow $=$ Tidal Volume/ Inspiratory time (Ti).

For $8 \mathrm{ml} / \mathrm{kg}$, Tidal volume $=464.8 \mathrm{ml}=484.8 \mathrm{ml}=0.48481$

Inspiratory time $\mathrm{Ti}=1 \mathrm{~s}$

Flow $=0.4848 / 1=0.48481$

\section{RESUlt AND DISCUSSION}

The volume of air given to a patient was calculated based on their ideal weight and height to avoid over ventilating or causing pressure build up in their airway. For example, if a tidal volume of $500 \mathrm{~mL}$ is given at $15 \mathrm{bpm}$, a patient will trigger the machine to deliver a breath every four (4) seconds. The tidal volume, the inspiratory time and the BPM is set by the operator or the clinical practitioner in charge of the patient. The pressure relief valve attached the pressure regulator limit airway pressure exceeding $35 \mathrm{cmH} 2 \mathrm{O}$. Additional breath will not be delivered if there is a buildup of pressure in the airway which could inflict more injury to the lungs. A difference in pressure is sensed by the differential pressure and sends a signal to the microcontroller and an alarm system is also incorporated to raise awareness. This makes possible to make adjustment in the ventilaory settings and clinical judments based on the alarm raised.

\section{Comparative ANalysis OF VARIOUS Ventilator}

T A standard hospital grade is expected to cost about $\$ 25,000$ to $\$ 35,000$ per unit. However, due to this exorbitant rate, this has hindered most countries especially developing nations from acquiring enough ventilators which would serve patients in dire need of it. The sudden surge in the pandemic which hit the globe last year made it more unavailable and inaccessible to acquire. As a result of this a low cost ventilator was developed and a comparison was made between the existing hospital grade and the low cost grade ventilator designed by other researchers who are in a quest to save lives. Cost analysis of various mechanical ventilators are shown in Table 2. A cost effective ventilator with the basic ventilatory parameters which was built with readily sourced components can also perform the basic function of a standard ventilator. This can be upscaled when the need arises.

Table 2: Cost Analysis for various Mechanical Ventilators

\begin{tabular}{|cll|}
\hline $\mathrm{s} / \mathrm{n}$ & Performance & \multicolumn{1}{l|}{$\begin{array}{l}\text { Cost } \\
(\$)\end{array}$} \\
\hline 1 & LTV 950 ventilator & 773.00 \\
\hline 2 & Resmed ventilator & 587.63 \\
\hline 3 & ms p120 Ventilator & 800.00 \\
\hline & Hartwell surevent & \\
& Emergency Transport & \\
\hline 4 & Ventilator & 640 \\
\hline 5 & Mine & 415 \\
\hline
\end{tabular}




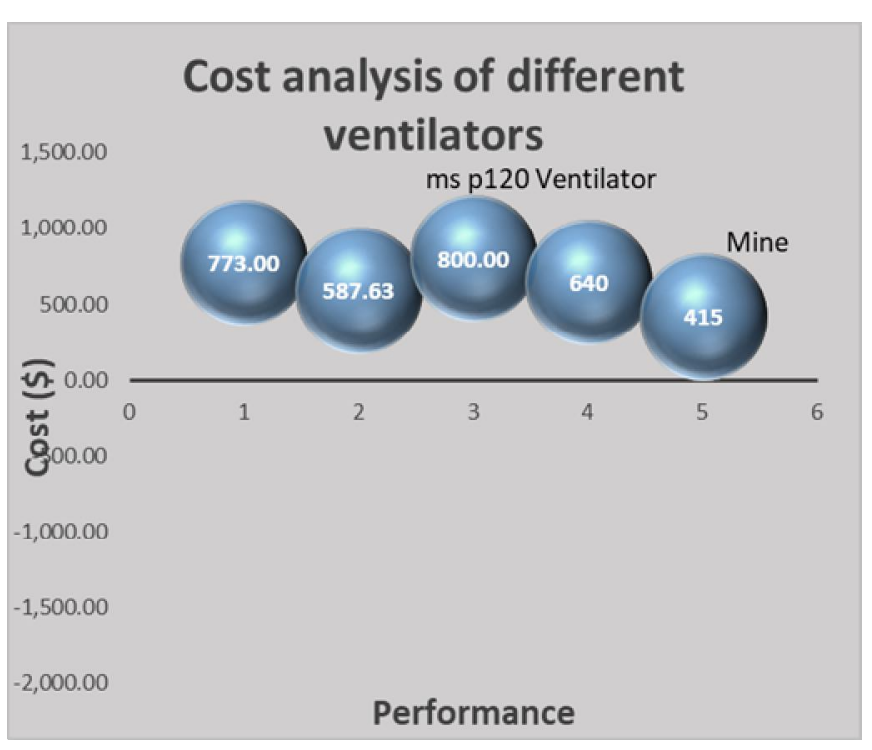

Figure 3: Cost-Performance Distribution of Ventilators

\section{CONCLUSION}

The technique used in present work proves to be more effective as it provide an understanding on the human physiological behavior and the importance of ventilation in rescuing patients with various respiratory disorders and also established a comparative analysis of a standard ventilator against the developed ventilator in term of cost, power consumption and durability.

i. The developed ventilator is a volume controlled ventilator in which the flow rate and the tidal volume is set by the clinician and the machine adapts pressure levels to meet those goals.

ii. An alarm system is built in the system to monitor high pressure that can cause lung induced injury such as barotrauma in a patient.

iii. It is portable, durable, has minimal noise level and also has low power consumption both in the idle and operating states of the ventilator.

iv. When compared to a standard ventilator, the cost of acquiring the developed ventilator is lesser and can be utilized in emergency cases or in areas where it is inaccessible and unavailable.

$\mathrm{v}$. The developed ventilator provides stable gas flow which is economical and free of contaminants

\section{REFERENCES}

1. R. M. Kacmarek, "The Mechanical Ventilator: Past, Present, and Future," RESPIRATORY CARE, vol. 56, no. 8, August 2011.

2. A. M. A. Husseini, H. J. Lee, J. Negrete, S. Powelson1, A. Servi, A. Slocum and J. Saukkonen, "Design and Prototyping of a Low-cost Portable Mechanical
Ventilator," in Design of Medical Devices Conference, Minneapolis, 2010

3. Bhakti K Patel, John P Kress,Jesse B Hall (2020). Alternatives to invasive ventilation in the COVID-19 Pandemic. Jama2324(1),43-44

4. S. Fludger and A. Klein, "Portable Ventilators," Continuing Education in Anaesthesia, Critical Care \& Pain, vol. 8, no. 6, pp. 199-203, 2008.

5. Kondili E, Prinianakis G, Alexopoulou C, Vakouti E, Kilmanthianaki M, Georgopoulos D. (2006). Respiratory load compensation during mechanical ventilation: proportional assist ventilation with load adjustable gain factors versus pressure support. Intensive Care Med ;32(5):692-699

6. L. A. Geddes. (2007) "The history of artificial respiration," EEE ENGINEERING IN MEDICINE AND BIOLOGY MAGAZINE, 2007

7. Perme, C., \& Chandraskekar, R.K. (2008). Managing the patient on mechanical ventilation in ICU: Early mobility and walking program. Acute Care Prospectives, Vol 17(1).

8. Cannon ML, Cornell J, Tripp-Hamel DS, et al. (2000). Tidal volumes for ventilated infants should be determined with a pneumotachometer placed at the endotracheal tube. Am JRespir Crit Care Med; 162: 2109-2112.

9. Randerath WJ, Galetke W, Kenter M, Richter K, Schafer T. (2009) Combined adaptive servo-ventilation and automatic positive airway pressure (anticyclic modulated ventilation) in co-existing obstructive and central sleep apnea syndrome and periodic breathing. Sleep Med; 10(8):898-903

10. Sternbach GL, Varon J, Fromm RE, Sicuro M, Baskett PJ. (2001). Galen and the origins of artificial ventilation, the arteries and the pulse. Resuscitation, 49:119-122.

11. Spahija J, de Marchie M, Albert M, Bellemare P, Delisle S, Beck J, et al. (2010). Patient-ventilator interaction during pressure support ventilation and neurally adjusted ventilatory assist. Crit Care Med ;38(2):518-526

12. Borges JB, Okamato VN, Matos GF, Carney MP, Arantes PR, Barros F, et al. (2006). Reversibility of lung collapse and hypoxemia in early acute respiratory distress. Am J Respir Crit Care Med; 174(3):268-278

13. Azeta, J., Christian, B., Abiodun, A. A., \& Oyawale, F. (2018). A review on humanoid robotics in healthcare. MATEC Web of Conferences, 153.

14. Azeta, J., Bolu, C., Hinvi, D., \& Abioye, A. A. (2019). Obstacle detection using ultrasonic sensor for a mobile robot. IOP Conference Series: Materials Science and Engineering, 707(1). 